\title{
Importance of Multidetector Computed Tomography in the Diagnosis of a Small Intestinal Tumor
}

\author{
Seitaro Watanabe ${ }^{a}$ Hirokazu Takahashi ${ }^{a}$ Yasunobu Abe $^{a}$ Masahiko Inamori ${ }^{a}$ Tomoko Koide $^{a}$ \\ Chikako Tokoro $^{a}$ Kunihiro Hosono ${ }^{a}$ Hiroki Endo ${ }^{a}$ Noritoshi Kobayashi ${ }^{a}$ Hiroyuki Kirikoshi $^{\mathrm{a}}$ \\ Kensuke Kubota ${ }^{a}$ Satoru Saito $^{a}$ Nobuhiro Sugano $^{b}$ Yasushi Rino $^{\text {b }}$ Takashi Nakayama $^{c}$ \\ Yoshiaki Inayama ${ }^{c}$ Atsushi Nakajima ${ }^{a}$ \\ ${ }^{a}$ Gastroenterology Division and ${ }^{b}$ Division of Surgery, Yokohama City University School of Medicine, and ${ }^{\mathrm{C}}$ Department of \\ Pathobiology, Yokohama City University Graduate School of Medicine, Yokohama, Japan
}

\section{Dear Sir,}

A 35-year-old man was admitted to our hospital with complaints of vomiting, loss of appetite and weight loss. Abdominal $\mathrm{X}$-ray revealed small bowel gas and airfluid level. Horizontal and coronal sections of multidetector computed tomography $(\mathrm{MDCT})$ revealed an obstruction in the upper small intestine and an expansion of the oral side (fig. 1). The horizontal section was particularly suitable to identify the lesion and its relationship to surrounding organs. A small intestinal tumor was suspected, so single-balloon endoscopy was performed. A type 2 tumor was located $100 \mathrm{~cm}$ distal to the pylorus ring. Partial small-bowel resection was carried out, and the tumor was $6 \times$ $2.5 \mathrm{~cm}$ in diameter macroscopically. The tumor was a proliferating well-differentiated adenocarcinoma with a partially formed comb-like lumen, and it had invaded the serous membrane.

CT plays an important role in the diagnosis of patients with acute abdominal pain, and especially MDCT can evaluate the small intestine in detail [1]. The thin-slice imaging that is possible with MDCT is most effective in identifying regions of intestinal obstruction [2]. Coronal section imaging by MDCT is useful for specifying the location of the lesion and making a qualitative diagnosis.

References $>_{1}$ Horton KM, Fishman EK: Multidetectorrow computed tomography and 3-dimensional computed tomography imaging of small bowel neoplasms. J Comput Assist Tomogr 2004;28:106-116.

-2 Minordi LM, Vecchioli A, Mirk P, Filigrana E, Poloni G, Bonomo L: Multidetector CT in small-bowel neoplasms. Radiol Med 2007; 112:1013-1025.

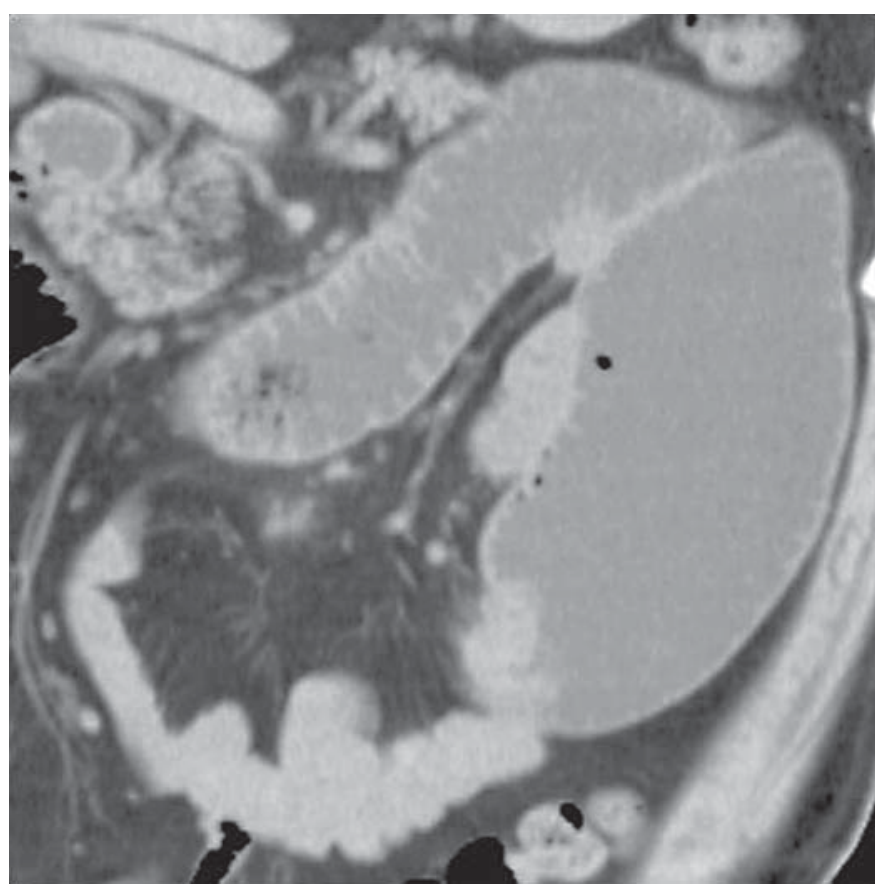

Fig. 1. Computed tomography (coronal section) view reveals the obstruction in the upper small intestine and the expansion of the oral side.

\section{KARGER}

Fax +41613061234 E-Mail karger@karger.ch www.karger.com 